\title{
CONSULTORIA EM RECURSOS HUMANOS: TREINAMENTO E DESENVOLVIMENTO DE PESSOAS
}

\author{
HUMAN RESOURCES CONSULTANCY: TRAINING AND DEVELOPMENT OF \\ PEOPLE
}

\section{Diogo Costa Pereira ${ }^{1}$}

\begin{abstract}
RESUMO: Este é um estudo sobre Consultoria em Recursos Humanos: treinamento e desenvolvimento de pessoas, tendo como eixo de investigação a fundamentação teórica. O principal objetivo foi demonstrar a necessidade de inserção de profissionais de consultoria no setor de Recursos Humanos das organizações com vistas ao treinamento e desenvolvimento de pessoas. O universo pesquisado foi de revisão de literatura através de consulta em livros, teses, dissertações, artigos, revistas eletrônicas e sítios da internet. Adotada a metodologia de revisão bibliográfica acredita-se ter revisado um conhecimento que favoreça aproximações com questões dinâmicas que relacionam o alinhamento do $\mathrm{RH}$ às estratégias organizacionais das empresas através do treinamento e desenvolvimento de pessoas. Consolidou-se que a ação do Consultor de RH detectando deficiências, treinando e desenvolvendo as competências e habilidades é imprescindível para alinhar os funcionários aos objetivos organizacionais.
\end{abstract}

Palavras-Chave: Consultoria. Treinamento. Desenvolvimento. Novo Recursos Humanos.

ABSTRACT: This is a study on Human Resources Consultancy: training and development of people, with the theoretical foundation as the research axis. The main objective was to demonstrate the need for insertion of consulting professionals in the Human Resources sector of organizations with a view to training and developing people. The universe researched was a literature review through consultation in books, theses, dissertations, articles, electronic magazines and websites. Adopted the bibliographic review methodology, it is believed to have revised knowledge that favors approaches with dynamic issues that relate the alignment of HR to the organizational strategies of companies through the training and development of people. It was consolidated that the HR Consultant's action detecting deficiencies, training and developing competences and skills is essential to align employees with organizational objectives.

Keywords: Consulting. Training. Development. New Human Resources.

\section{INTRODUÇÃO}

A partir da industrialização, nos países desenvolvidos, ainda, no século XIII o mundo empresarial vem, a cada década, sofrendo fortes transformações na busca da produtividade, do lucro

\footnotetext{
${ }^{1}$ Graduado em Análise e Desenvolvimento de Sistemas (IFTM - Campus Patrocínio), graduado em Gestão Financeira (UNICESUMAR), pós-graduando em Tecnologia de Produção Cervejeira (CLARETIANO), pósgraduado em Marketing (UNICESUMAR), pós-graduado em Tecnologias para Aplicações Web (UNOPAR) e pós-graduado em Consultoria Empresarial: ênfase em R.H (UNICERP). Email: diogocostapereira@gmail.com.
} 
e solidez diante de um mercado, cada vez mais competitivo. Não obstante, essas modificações contínuas nunca se presenciaram mudanças tão profundas como se vê na atualidade, na chamada era do conhecimento.

Neste contexto, a valorização do capital humano tem sido notada como estratégia para as empresas, pois as pessoas são consideradas pelos gestores o principal patrimônio destas organizações. Assim, é cada vez mais real a necessidade de pessoas capacitadas que possam produzir e prestar serviços eficientes, sendo cada vez mais frequente o investimento em treinamento e desenvolvimento de pessoal.

$\mathrm{O}$ antigo departamento de Recursos Humanos $(\mathrm{RH})$, responsável pela burocracia que envolve as questões legais inerentes ao vínculo empregatício, deu lugar a um setor responsável pelo recrutamento, treinamento, aperfeiçoamento de cargos e salários, responsável em alinhar as competências, habilidades e ansiedades dos colaboradores aos objetivos estratégicos das organizações, necessitando, portanto, de profissionais altamente especializados capazes de exercerem a chamada consultoria interna de recursos humanos (MARRAS, 2000).

A Consultoria Interna em Recursos Humanos foi ampliada e já é comum nas grandes organizações (LEITE, et al. 2005), ficando o consultor responsável por promover e facilitar o treinamento e desenvolvimento de pessoal; fornecer informações; facilitar a comunicação organizacional; prever acontecimentos através de tendências do mercado e antecipar ações eficazes; dar suporte às áreas e gestores para atingirem os objetivos e os resultados estabelecidos (OLICKAS, 2010).

Assim, o presente estudo teve como objetivo demonstrar, através de revisão de literatura, a evolução do setor de Recursos Humanos e a necessidade de inserção de profissionais de consultoria neste setor organizacional das grandes empresas com vistas ao treinamento e desenvolvimento.

Acredita-se que este estudo possa aproximar informações relevantes que associem a ação do Consultor Interno de Recursos Humanos ao aperfeiçoamento dos funcionários na eficácia dos processos organizacionais através do treinamento e desenvolvimento de pessoal e ainda incrementar a produção científica em torno do tema.

\section{AS ORGANIZAÇÕES E AS CAPACIDADES HUMANAS}

No decorrer do século $\mathrm{XX}$ as organizações passaram por períodos distintos: tem-se a Industrialização clássica de 1900 a 1950, marcada principalmente pela Revolução industrial; a Industrialização Neoclássica que vai de 1950 a 1990, caracterizada por: maiores transações comerciais; 
ênfase nas relações humanas; competição acirrada entre as empresas e maior flexibilidade na estrutura organizacional (LOURES JÚNIOR, 2012).

A partir de 1990, com os profundos avanços tecnológicos atingidos pela internet, a informação passa a circular com vertiginosa rapidez, vive-se, como nunca, a era do conhecimento (LARA, 2004). Para Loures Júnior (2012, p. 3) nesta nova fase das organizações "os processos organizacionais tornaram-se mais importantes do que os órgãos que constituem a organização".

Assim, as capacidades humanas aparecem no mercado de trabalho, cada vez mais globalizado, como estratégia competitiva entre as organizações (CHIAVENATO, 2002). Entretanto, Dutra (2006) considera que estas capacidades surgem a partir do resgate do papel do ser humano na organização. Para o autor, é a partir da valorização do capital humano que surge o conceito de gestão de pessoas tal qual se busca atualmente.

As empresas mais expostas a mudanças ambientais já desenvolvem trabalhos com equipes multifuncionais, com atividades provisórias voltadas para missões específicas e com objetivos definidos. As organizações do futuro vão funcionar sem limite de tempo, espaço ou distância. Hoje e com certeza com mais ênfase no futuro, o recurso mais valorizado será o conhecimento humano. Ele é fonte inesgotável de energia (rentabilidade sobre o conhecimento). As pessoas com suas habilidades e competências tornaram-se a nova base da organização (LOURES JÚNIOR, 2012, p. 3).

Neste contexto, a qualificação dos profissionais se apresenta como fator primordial (ORLICKAS, 2010). Se por um lado, o setor de Recursos Humanos (RH) era visto como departamento mecanicista de suporte operacional e meramente burocrático, atualmente, esse setor pode ser visto como a alma da empresa, pois com os modernos conceitos de gestão de pessoas, o RH passou a cuidar da seleção, contratação e treinamento dos profissionais envolvidos no processo (CHIAVENATO, 2005).

Diante disso, os profissionais responsáveis pelo RH necessitam de um programa continuado de capacitação, abrindo espaço para a consultoria em RH.

\section{I Recursos humanos e gestão de pessoas}

A administração de recursos humanos (ARH) teve seu início, nos Estados Unidos da América (EUA) em I89o com o surgimento do primeiro Departamento de Administração de Pessoal na NCR Corporation devido à eminente exigência de controlar os custos relacionados com o trabalho dos empregados (FISCHER, 1998). Para Marras (2000) a ARH surgiu a partir da necessidade de contabilizar as entradas de empregados na organização, sendo mais importante controlar as horas trabalhadas, as faltas ao emprego e atrasos para efeito de descontos nos pagamentos. 
As modificações relacionadas ao comportamento dos operários de uns para com os outros e com a própria organização; o surgimento do movimento sindical; e as grandes mudanças no Estado Americano ocorridas a partir da grande depressão, podem ser considerados fatores que influenciaram, fortemente, a efetivação da ARH como área autônoma dentro das organizações (SAMMARTINO, 2002).

Segundo Tose (1997, apud MARRAS, 200o) pode-se destacar cinco fases na evolução do perfil profissional de RH:

a) Fase contábil: durou até a década de I930 que teve a administração científica como precursora, entretanto, se ateve aos dados contábeis, registros de entrada e saída de pessoal para controle dos processos.

b) Fase legal: da década de 1930 até 1950 houve o surgimento do chefe de pessoal que intermediava as relações entre empresa e empregado, período que, no Brasil, já vigorava a legislação trabalhista através da Consolidação das Leis do Trabalho instituída no Governo de Getúlio Vargas.

c) Fase tecnicista: de1950 a 1965 neste modelo o RH passa a ter o foco em treinamento, seleção, recrutamento, entre outros. Forte ascensão do Gerente de Relações Industriais.

d) Fase administrativa ou sindicalista: de 1965 a 1985 esta fase foi marcada pelo fortalecimento dos sindicatos, o Gerente de Relações Industriais passa a ser Gerente de Recursos Humanos, as relações humanas, a valorização do indivíduo e da sociedade passa a vigorar em detrimento do caráter burocrático, técnico e legal, anteriormente evidenciados.

e) Fase estratégica: deı1985 até 1990 esta fase caracterizou-se pelo surgimento dos planejamentos estratégicos nas organizações, estes planejamentos fizeram com que as diretorias passassem a criar ações a longo prazo tanto para as empresas quanto para os indivíduos.

A partir da fase estratégica a área de RH passa a assumir tarefas como recrutamento, treinamento, desenvolvimento, cargos e salários. As forças do ambiente e a competição internacional e nacional passam a exercer forte influência. Assim, o profissional de RH começa a alinhar suas funções aos objetivos estratégicos da empresa devido às imposições do mercado, tendo como objetivo facilitar a flexibilidade e adaptação dos trabalhadores às mudanças organizacionais e ambientais (DAVEL e VERGARA, 2006).

Surge, portanto, forte distinção entre empresas tradicionais e as novas organizações, sendo que estas respondem as pressões das mudanças no macroambiente organizacional com desenvolvimento sistemático de habilidades reunidas através do treinamento para operação, o que faz surgir às chamadas competências (ROCHA-PINTO et al., 2003). Esta nova forma de gerir denominada Administração Estratégica de Recursos Humanos, privilegia "a otimização dos resultados finais da empresa e da qualidade dos talentos que a compõem" (MARRAS, 200o, p. 253). 
Ao falar sobre gerenciamento estratégico de recursos humanos, Santos (1998) já considerava um redesenho da organização e dos cargos. Para o autor, a empresa teria que elaborar seu plano de carreira com foco no indivíduo e não no cargo, pois, o valor passaria a ser dado ao indivíduo em detrimento do cargo que ele ocuparia proporcionando à organização maior flexibilização para alocar os trabalhadores em projetos e áreas valorizando, portanto, os talentos de cada indivíduo.

Fonseca (2007), ao desenvolver estudo de caso sobre gestão de pessoas na Gerdau, com 92 líderes e 9 profissionais de $\mathrm{RH}$, considera que as organizações têm encontrado grandes desafios na busca de novos caminhos para se manterem no mercado globalizado e competitivo, sendo que:

[...] o atual desafio do RH ainda consiste em reforçar a consistência interna e externa de suas funções e processos, buscando alinhá-los à estratégia da organização, em parceria com as lideranças, na gestão das dualidades e paradoxos inerentes ao processo de globalização (FONSECA, 2007, p. 7).

Diante disso, com o capital humano, cada vez mais, sendo valorizado dentro das organizações é natural que dentro da consultoria empresarial a consultoria interna em RH torne-se forte aliada no rompimento dos desafios que ora se apresentam.

\section{${ }_{3}$ CONSULTORIA EMPRESARIAL}

A atividade de consultoria se confunde com o próprio desenvolvimento e evolução da humanidade, pois sempre se teve notícias de conselheiros ou consultores dos reis, rainhas, religiosos e líderes em geral. Entretanto, Mancia (1997) considera que a atividade, tal qual deva ser considerada, surgiu na década de so do século XX na área médica de saúde mental coletiva e que, posteriormente, migrou para a área organizacional, tendo surgido em países industrializados com economia de livre comércio, especificamente, em empresas privadas, e que, posteriormente atingiu, também, as empresas públicas e os países socialistas, tornando-se uma atividade de grande relevância no meio empresarial.

Para Caplan (1970 apud MANCIA, 1997) a atividade de consultoria empresarial pode ser vista como uma interação entre dois profissionais, ou seja, o consultor que é um especialista e o consultado que solicita as informações deste profissional referente a algum problema de trabalho do momento, com o qual ele enfrenta e que não se encontra dentro de sua especificidade, necessitando, portanto, de um conselho de alguém que entenda mais sobre aquele determinado assunto.

Orlickas (2010) define consultoria organizacional como sendo o fornecimento de prestação de serviço feito por um profissional qualificado (especializado), com remuneração, que se processa através de diagnósticos e processos com objetivo de identificar as necessidades organizacionais, indicar soluções, recomendar ações, e ainda, implantá-las e acompanhá-las. Note-se que para 
implantar ações, em se tratando de treinamento e desenvolvimento o consultor deverá criar métodos que as promovam.

A consultoria pode ser: organizacional quando a atividade é investigativa, de identificação, estudo e solução de problemas relativos à estrutura, ao funcionamento e a administração de empresas e entidades privadas ou estais; autônoma quanto realizada por profissional qualificado que atua em determinado projeto sem vínculo a estrutura organizacional; associada que se caracteriza por trabalho de consultoria desenvolvido por uma empresa; externa quando realizada por profissional não integrante da empresa ao qual presta serviço; interna exercida por funcionário da empresa que: desempenha atividades de facilitação, elabora diagnóstico e busca soluções para os problemas e, por fim, a consultoria exclusiva exercida por profissional que oferece aconselhamento a uma determinada empresa (CROCCO e GUTTMANN, 2005).

\section{I Consultoria interna em $\mathrm{RH}$, treinamento e desenvolvimento de pessoas}

Diante dos inúmeros desafios que as organizações enfrentam, em tempos de grandes e efetivas mudanças, a processo de Gestão de Pessoas cresce progressivamente, abrindo espaço para a atuação do profissional de RH como consultor interno, capaz de efetivar mudanças, catalisar a energia e o conhecimento dos colaboradores, melhorar e ampliar a estruturação organizacional, bem como a qualidade nos serviços com agilidade de execução (GIRARDI et al., 2009).

Neste sentido, Leite (et al., 2005) considera que as mudanças nos processos e nos sistemas realizadas pelos executores de tarefas dentro das organizações; a evolução tecnológica e o foco na qualidade ampliaram a importância da Consultoria na área de $\mathrm{RH}$, tornando-se responsável por ações estratégicas para o desenvolvimento organizacional.

A Consultoria Interna de Recursos Humanos procura: melhorar o atendimento ao cliente interno; fornecer informações à organização; facilitar a comunicação organizacional prever acontecimentos através das tendências do mercado e antecipar ações eficazes; dar suporte às áreas e gestores para atingirem os objetivos e resultados estabelecidos e promover e facilitar o treinamento e desenvolvimento de pessoal (ORLICKAS, 2010).

Além disso, a Consultoria Interna em Recursos Humanos é uma alternativa que possibilita o crescimento organizacional, pois, procura responder com eficiência às demandas da organização, agregando valores através do conhecimento aprofundado dos problemas da empresa, contribuindo para a produtividade e sucesso da organização, tendo como objetivo os negócios, a aprendizagem e o desenvolvimento organizacional (GIRARDI, et al 2009). Desta forma, a Consultoria Interna em 
Recursos Humanos utiliza-se do treinamento empresarial para atingir a aprendizagem e o desenvolvimento organizacional.

O treinamento empresarial pode ser entendido como um processo que permite aos indivíduos desenvolverem conhecimentos, habilidades e atitudes para o desempenho de suas funções profissionais (CHIAVENATO, 2002). É um processo educacional, pois, visa formação e preparação das pessoas para o desempenho do cargo que pode ser atual ou futuro dentro da empresa (LOURES JUNIOR, 2012).

O treinamento, como processo educacional, pode ser por transmissão de informações e conhecimentos necessários ao cargo, sobre a empresa, seus produtos e serviços, suas regras e regulamentos internos, sua missão, dentre outros; desenvolvimento de habilidades e destrezas na utilização de equipamentos preenchimento de formulários, execução de cálculos, operação de máquinas, dentre outros; e desenvolvimento de atitudes, ou seja, mudança de atitudes negativas nas relações humanas para atitudes positivas e favoráveis para melhorar ou facilitar o relacionamento com colegas, clientes subalternos e chefia (LOURES JUNIOR, 2012).

Para Chiavenato (2002) o treinamento é constituído de fases que se inicia na determinação das necessidades devido à baixa produtividade do pessoal ou da qualidade do trabalho; comunicação deficiente; excesso de erros; grande incidência de acidentes; estragos em máquinas e equipamentos por mau uso; problemas de relacionamento entre as pessoas. Após ser determinada a necessidade, ocorre a programação do treinamento, sua execução e, posteriormente, a avaliação dos resultados.

Para que o treinamento atinja seus objetivos é importante que o Consultor Interno de RH indique a melhor técnica de treinamento, sendo as mais comuns: aulas expositivas com recursos audiovisuais; demonstrações, normalmente utilizadas quando se necessita transmitir conhecimentos para operar máquinas e equipamentos; leitura programada de textos ou livros previamente indicados; instrução programada que se baseia em grupos de informações seguidos por testes de aprendizagem e por último a dramatização que é baseada no faz de conta, ideal para cargos que exigem contato com pessoas (LOURES JUNIOR, 2012). O autor considera que é comum a utilização de várias técnicas combinadas.

O importante é que o programa de treinamento seja bem sucedido, uma vez que, é através dele que ocorrerá a melhoria de eficiência nos serviços, obtenção de melhores resultados, qualidade de vida no trabalho, grande produtividade com alto padrão de qualidade e serviços inovadores oferecidos ao mercado, maior competitividade organizacional (CHIAVENATO, 1999).

Se os problemas diagnosticados como, por exemplo, baixa produtividade, baixa qualidade e elevado índice de manutenção de máquinas e equipamentos, elevados índices de acidentes no trabalho etc. foram eliminados, então o treinamento foi eficaz e surtiu os efeitos desejados. Se, porém, os problemas diagnosticados 
permanecem após o treinamento, então alguma coisa saiu errada: ou o diagnóstico foi mal feito, ou a programação não foi correta, ou então a execução do treinamento foi precária. (LOURES JUNIOR, 2012, p. 40).

Desta forma, cabe ao Consultor Interno de Recursos Humanos avaliar os resultados e verificar quais as fases do treinamento não surtiram efeito, tendo, portanto, que reprogramá-las. Chiavenato (I999) considera que além de se observar os métodos do treinamento o Consultor Interno de Recursos Humanos deve agregar valor às pessoas e às organizações envolvendo ativamente os gerentes e suas equipes nos conteúdos do programa de treinamento e desenvolvimento.

Por fim, o treinamento e desenvolvimento de pessoal orientado por um Consultor Interno de RH em uma organização não pode ser ato isolado em tempos de problemas e dificuldades, pelo contrário, tem de ser uma atividade contínua, sem interrupções, até mesmo quando os resultados são excelentes, sempre haverá pontos que se pode melhorar através de orientações precisas em direção ao sucesso que só se dará com apoio gerencial e trabalho em sintonia com a cultura e objetivos da organização (ULRICH, 200o).

\section{${ }_{4}$ CONSIDERAÇÕES FINAIS}

$\mathrm{Na}$ era do conhecimento o capital humano passou a ser considerado um dos principais ativos das organizações, necessitando de treinamento e aperfeiçoamento para se alinhar aos objetivos organizacionais. Neste sentido, o setor de Recursos Humanos torna-se uma condição fundamental para a gestão das organizações, necessitando, portanto, de profissionais ainda mais capacitados e especializados.

No decorrer deste estudo foi possível perceber que a Consultoria Interna em Recursos Humanos surgiu como forte instrumento para buscar mais agilidade e eficácia nos processos empresariais diante de organizações com departamentos fragmentados. Tornando de grande relevância o aprofundamento a respeito do tema estudado.

Este estudo apontou também para a importância, necessidade e possibilidade do consultor interno em RH poder facilitar a implantação de um modelo de gestão por competências deixando de ser um departamento meramente gerencial ou tático, mas que trabalhe a partir dos desafios estratégicos e do posicionamento de mercado e que possa extrair as competências consideradas imprescindíveis para implantação da estratégia.

Ademais, cabe à consultoria em RH analisar as lacunas existentes entre as competências atuais e aquelas alusivas a estratégia da empresa, buscando preencher estes espaços criando um ciclo de desenvolvimento de competências através de treinamentos sistematizados orientadas pela estratégia. 
Acreditar-se também que possa haver a possibilidade de avanços em trabalhos futuros com inclusão de pesquisas de campo e estudos de caso, trazendo os conceitos verificados na literatura para constatações práticas a respeito do tema.

Assim, esta investigação, tendo trazido à tona, a importância da consultoria na detecção de problemas, implantação de métodos de treinamento e desenvolvimento de pessoas, bem como a avaliação dos resultados para se atingir alto grau de eficácia organizacional.

\section{REFERÊNCIAS BIBLIOGRÁFICAS}

CHIA VENATO, I. Comportamento Organizacional: a dinâmica do sucesso das organizações. 2 ed. Rio de Janeiro: Elsevier. 2005. , Recursos humanos. edição compacta, 7. ed., SP, Atlas, 2002

Campus, 1999 .

Gestão de Pessoas: O novo papel dos recursos humanos nas organizações. Rio de Janeiro:

CROCCO, Luciano; GUTTMANN, Erick. Consultoria Empresarial. Saraiva, 2005.

DAVEL, E.; VERGARA, S. C. (Orgs.). Gestão com pessoas e subjetividade. São Paulo: Atlas, 2006.

DUTRA, Joel Souza. Gestão de pessoas: modelo, processos, tendências e perspectivas. São Paulo: Atlas, 2006.

FISCHER, R.A. CONSTRUÇÃO DO MODELO COMPETITIVO DE GESTÃO DE PESSOAS NO BRASIL: um estudo sobre as empresas consideradas exemplares. 1998. $230 \mathrm{f}$. Tese (Doutorado em Administração) Universidade de São Paulo- USP, São Paulo.

FONSECA, E. de L. Gestão de pessoas na Gerdau: um estudo de caso. 2007. I6o f. Dissertação (Mestrado Profissional em Administração) Faculdades Integradas de Pedro Leopoldo, Pedro Leopoldo, MG.

GIRARDI, D. M.; LAPOLLI, E. M.; TOSTA, K. C. B. T. A Consultoria Interna de Recursos Humanos como Prática Catalisadora da Gestão do Conhecimento Organizacional. Revista de Ciências da Administração. v. II, n. 25, p. I21-150, set/dez 2009

LARA, C. R. D. de. A atual gestão do conhecimento. São Paulo: Nobel, 2004.

LEITE, L. A. M. da C. et al. Consultoria em Gestão de Pessoas. Rio de Janeiro: Editora FGV, 2005.

LOURES JÚNIOR, J. de A. R. Administração de recursos humanos: visão sistêmica em gestão de pessoas. 5. ed.,SP, CEEP - FCM, 2012.

MANCIA, L. T. S, Os desafios do modelo de consultoria interna: uma experiência gaúcha. 1997. I84 f. Dissertação (Mestrado em Administração) Universidade Federal do Rio Grande do Sul, Porto Alegre.

MARRAS, J. P. Administração de recursos humanos: do operacional ao estratégico. 3.ed. São Paulo: Futura, 200o.

ORLICKAS, E. Consultoria de recursos humanos: conceitos, casos e estratégias. Io. ed. São Paulo: Danelli, 2010. 
ROCHA-PINTO, S. R. da; PEREIRA, C. de S.; COUTINHO, M. T. C.; JOHANN, S. L. Dimensões funcionais da gestão de pessoas. Rio de Janeiro: FGV, 2003.

SAMMARTINO, W. A INTEGRAÇÃO DO SISTEMA DE GESTÃO DE RECURSOS HUMANOS COM AS ESTRATÉGIAS ORGANIZACIONAIS. 2002. $270 \mathrm{f}$. Tese (Doutorado em Administração) - Universidade de São Paulo - USP, São Paulo.

SANTOS, F. C. A. DIMENSÕES COMPETITIVAS DA ESTRATÉGIA DE RECURSOS HUMANOS: importância para a gestão de negócio em empresas manufatureiras. 1998. 357 f. Tese (Doutorado em Administração) Escola de Engenharia de São Carlos/USP. São Carlos, 1997.

ULRICH, D. Recursos humanos estratégicos: novas perspectivas para os profissionais de RH. São Paulo: Futura, 2000. 